\title{
Concentration of MMP-8 and IL-1 $\beta$ in gingival crevicular fluid in patients with chronic and aggressive periodontitis
}

\author{
MAEGORZATA NĘDZI-GÓRA ${ }^{l}$, RENATA GÓRSKA ${ }^{1}$, JOLANTA KOSTRZEWA-JANICKA², \\ JAN KOWALSKI
}

${ }^{1}$ Department of Periodontology and Oral Diseases, Medical University of Warsaw, Poland

${ }^{2}$ Department of Prosthodontics, Medical University of Warsaw, Poland

\begin{abstract}
Modern research confirms the role of inflammatory mediators in the pathomechanism of periodontal tissue destruction. The aim of the study was to determine concentrations of MMP-8 and IL-1 $\beta$ in gingival crevicular fluid (GCF) in patients with advanced chronic and aggressive periodontitis. The authors measured the concentrations of the above inflammatory mediators in gingival crevicular fluid of deep pockets $(P D \geq 6 \mathrm{~mm})$ and shallow pockets $(P D 4-5 \mathrm{~mm})$ in 33 patients with advanced chronic periodontitis and in 16 patients with aggressive periodontitis. The control group consisted of 16 individuals with healthy periodontium. In all patients levels of MMP-8 and IL-1 $\beta$ in GCF were determined with the ELISA method. The study showed significantly higher concentrations of MMP-8 and IL-1 $\beta$ in GCF of both deep and shallow pockets in patients with periodontitis compared to healthy subjects. No difference in concentrations of the tested mediators was observed with reference to diagnosis of aggressive periodontitis $(A P)$ or chronic periodontitis $(C P)$.
\end{abstract}

Key words: periodontitis, markers, gingival crevicular fluid.

(Centr Eur J Immunol 2017; 42 (4): 342-346)

\section{Introduction}

Periodontal disease is a condition caused by an imbalance between oral microbiota and the inflammatory reaction. Antigens trigger an inflammatory response and its non-specific component is involved in the periodontal tissue damage [1]. The cells that most commonly participate in the non-specific inflammatory reaction are neutrophils and macrophages. A macrophage can be described briefly as a settled form of a monocyte [2]. Mouse species lacking macrophage-colony stimulating factor are significantly more prone to a fatal outcome of the infections [3]. The two main functions of macrophages are either to directly digest the pathogen (phagocytosis) or to transport the antigen to the draining lymph node in order to develop a specific inflammatory response in the case of future infection/contact (presenting the antigen) [2]. They are also involved in the bone remodeling pattern, and the op/op mice (without granulocyte colony stimulating factor) suffer from osteoclast malfunction [3]. Cytokines may be described as mediators of the immunological system. The vast majority of cytokines enhance the immunological response. Among them the key role is played by interleukin-1 (IL-1). The impor- tance of IL-1 stems not only from its name (cytokines were numbered in the order of their discovery) - its numerous features are much more important. Macrophages are not the only cells producing IL-1. Others include osteoclasts [4] and fibroblasts [5]. IL-1 inducts bone resorption via stimulating the receptor activator of nuclear factor kappa-B ligand (RANKL), which is the major activating signal for the osteoclasts [6]. It also increases the production of prostaglandin $\mathrm{E}_{2}$ in the bone tissue 'inhibits osteoclasts' apoptosis and upregulates the production of the macrophage colony stimulating factor [6].

The other cells belonging to the innate response are neutrophils. Thanks to the phenomenon of chemotaxis, neutrophils appear in the infected tissue and destroy the surroundings by means of superoxide anion production [7]. They also release several enzymes degrading connective tissue, called matrix metalloproteinases (MMP). Among those proteases is neutrophil collagenase (MMP-8), which breaks down collagen, the most important component of the periodontal ligament and bone.

As the junctional epithelium is permeable for neutrophils, and their presence in the junctional epithelium is

Correspondence: Małgorzata Nędzi-Góra, Department of Periodontology and Oral Diseases, Medical University of Warsaw, 18 Miodowa St., 00-246 Warsaw, Poland, e-mail: mnedzi-gora@wp.pl

Submitted: 9.01.2017; Accepted: 1.03.2017 
considered to be associated with the onset of the inflammation of periodontal tissues [8], it seems reasonable to detect the severity of the non-specific inflammatory response through detection of the main products of the innate immune response - IL-1 and MMP-8. Also, gingival crevicular fluid (GCF), being the filtrate of the serum, located in the exact spot of the contact between bacterial biofilm and host tissues, was found to be the most suitable place to seek potential disturbances in the inflammatory response.

The course of the mentioned phases of inflammation may differ in patients with advanced chronic periodontitis and in patients with aggressive periodontitis. Since the differentiation of these two periodontal disease is still based solely on periodontal examination, patient's history and radiographs, the aim of the study was to measure the levels of IL- 1 and MMP-8 in the GCF in patients suffering from aggressive periodontitis and chronic periodontitis.

\section{Material and methods}

After designing the study and obtaining the approval from the Ethical Committee of the Medical University of Warsaw, 49 individuals, aged 24-72 years (30 females and 19 males), were enrolled in the study group. They were selected according to the following criteria:

- diagnosis of advanced generalized chronic periodontitis (CP), or aggressive periodontitis (AP), according to the indications of the American Academy of Periodontology [9],

- at least one site with pocket depth (PD) $6 \mathrm{~mm}$ or higher,

- signing the informed consent.

The exclusion criteria were:

- smoking habit,

- suffering from an illness potentially affecting the immune response,

- antibiotic treatment within 3 months prior to the study,

- periodontal treatment within 12 months prior to the study,

- pregnancy.

The selected study group consisted of 16 individuals with diagnosed AP (aged 26-46 years) (11 females and 5 males) and 33 individuals suffering from CP (aged 24-72 years) (19 females and 14 males).

A control group was created, including individuals with healthy periodontium and no general diseases, who signed the informed consent. It consisted of 16 persons aged 21-32 years (9 females and 7 males).

Patients were subjected to a periodontal examination, during which standard clinical parameters were evaluated and recorded. No bleeding or plaque scores were evaluated, in order not to provoke blood exudation from the sampling sites, which would impair GCF collection. After the examination, a sample of gingival crevicular fluid (GCF) was collected from each individual. GCF was obtained:

- in the study group, from two sites: a "shallow pocket" a randomly chosen site with PD 4 or $5 \mathrm{~mm}$; and a "deep pocket" - the site with the highest $\geq 6 \mathrm{~mm}$ PD value in the whole dentition,

- in the control group, from the mesiobuccal point of the upper right first molar.

After careful removal of supragingival biofilm, the sampled pocket was dried for ten seconds with an air syringe. Then a paper point (Paperstrip, OraFlow Inc, USA) was inserted into the pocket and removed after 30 seconds. If the bleeding was provoked or the paper point was contaminated with saliva, the procedure was interrupted and repeated again.

Directly after collection the samples were inserted into a device dedicated to measurement of the volume of the collected GCF (Periotron 8000, OraFlow Inc., USA). The device utilizes the mechanism of an electrolytic capacitor. After inserting a paper point soaked with the fluid between the metal claws and fixing them, the distance between the claws stays constant. An electrical field generated by opposite charges on the surfaces of the claws causes polarization of the dipole of the studied fluid, which reduces the potential difference between the claws and changes their capacity. The recorded value is presented in Periotron units, proportional to the change of the electrolytic capacity. After drawing the calibration curve using known liquid volumes, the result is recalculated with SI units $(\mu l)$. The Periotron device was calibrated using standard volumes of human saliva $(0.25 \mu \mathrm{l} ; 0.5 \mu \mathrm{l} ; 0.75 \mu \mathrm{l} ; 1.0 \mu \mathrm{l} ; 1.25 \mu \mathrm{l})$ measured with a micropipette.

Directly after Periotron measurements, the paper points were inserted into tubes containing phosphate-buffered saline, for IL- $1 \beta$ and MMP-8 $200 \mu \mathrm{l}$ and $500 \mu \mathrm{l}$, respectively. The samples were frozen immediately to the temperature of $-20^{\circ} \mathrm{C}$ and stored until the biochemical testing.

GCF concentrations of IL-1 $\beta$ and MMP-8 were measured by an enzyme-linked immunosorbent assay (ELISA) using commercially available Quantikine kits (R\&D Systems, MN, USA) for quantitative determination of total human IL- $1 \beta$ and metalloproteinase. For MMP- 8 the test sensitivity was $0.06 \mathrm{ng} / \mathrm{ml}$, assay range $0.2-10 \mathrm{ng} / \mathrm{ml}-\beta$. For IL-1 sensitivity was $1 \mathrm{pg} / \mathrm{ml}$, assay range $3.9-250 \mathrm{pg} / \mathrm{ml}$.

Laboratory results were subjected to statistical analysis. Statistical evaluation to compare the levels of MMP-8 and IL- $1 \beta$ between 2 independent groups and between shallow and deep pockets was performed with the Mann-Whitney test. Spearman's correlation and Pearson's correlation coefficients were used to investigate intra-group relationships between levels of particular parameters. For the entire study the critical level of significance was assumed as $p=0.05$.

\section{Results}

Figure 1 presents mean concentrations of MMP-8 in the examined subgroups. In the shallow pocket group the level of MMP-8 was significantly higher (mean $45.0 \mathrm{ng} / \mu \mathrm{l}$, SD 41.2 vs. $14.4 \mathrm{ng} / \mu \mathrm{l}, \mathrm{SD} 16.5, p<0.001)$. Similarly, 


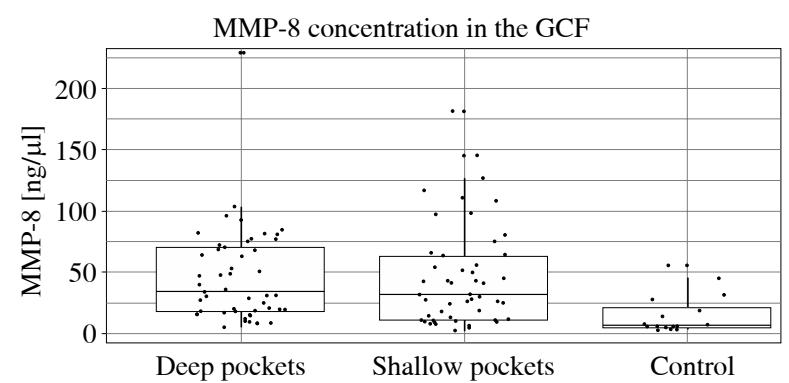

Fig. 1. Mean concentrations of MMP-8 levels in GCF in the shallow pockets ( $\mathrm{PD}=4-5 \mathrm{~mm}$ ), deep pockets $(\mathrm{PD} \geq 6 \mathrm{~mm})$ and healthy controls pockets. The level of MMP-8 in the shallow pockets was significantly higher (mean $45.0 \mathrm{ng} / \mu \mathrm{l}$, SD 41.2 vs. $14.4 \mathrm{ng} / \mu \mathrm{l}$, SD 16.5, $p<0.001)$ than in controls. Similarly, MMP-8 concentration in the GCF collected from deep pockets was also significantly higher than in controls (mean $46.4 \mathrm{ng} / \mu \mathrm{l}, \mathrm{SD}$ $38.6, p<0.001$ ). The values of MMP-8 concentrations in shallow and deep pockets did not differ $(p=0.798)$

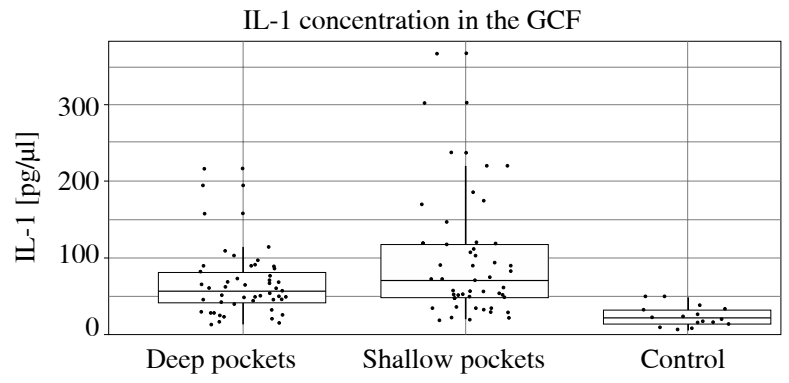

Fig. 2. Mean concentrations of IL-1 $\beta$ levels in GCF in the shallow pockets $(\mathrm{PD}=4-5 \mathrm{~mm})$, deep pockets $(\mathrm{PD} \geq 6 \mathrm{~mm})$ and healthy controls pockets. In shallow sites IL-1 $\beta$ concentration reached $92.9 \mathrm{pg} / \mu \mathrm{l}(\mathrm{SD}=74.6)$, in deep sites $64.1 \mathrm{pg} / \mu \mathrm{l}(\mathrm{SD}=41.5)$, and in both cases was significantly higher than in controls $(23.0 \mathrm{pg} / \mu \mathrm{l}$, $\mathrm{SD}=13.5, p<0.001)$. Statistical comparison of IL-1 $\beta$ levels in shallow and deep pockets revealed a significant difference $(p=0.002)$
MMP-8 concentration in the GCF collected from deep pockets was also significantly higher than in controls (mean $46.4 \mathrm{ng} / \mu \mathrm{l}$, SD 38.6, $p<0.001$ ). The values of MMP-8 concentrations in shallow and deep pockets did not differ $(p=$ 0.798).

Figure 2 illustrates a similar evaluation regarding IL-1 $\beta$ concentration. Again, both in shallow and deep pockets IL-1 $\beta$ levels in GCF were significantly higher in study subgroups than in controls. In shallow sites IL-1 $\beta$ concentration reached $92.9 \mathrm{pg} / \mu \mathrm{l}(\mathrm{SD}=74.6)$, in deep sites $64.1 \mathrm{pg} / \mu \mathrm{l}(\mathrm{SD}=41.5)$, and in both cases was significantly higher than in controls $(23.0 \mathrm{pg} / \mu \mathrm{l}, \mathrm{SD}=13.5$, $p<0.001)$. Statistical comparison of IL- $1 \beta$ levels in shallow and deep pockets revealed a significant difference $(p=0.002)$.

Table 1 shows the possible association between MMP-8 and IL-1 $\beta$ concentrations and the periodontal diagnosis. According to the Mann-Whitney test comparison, MMP-8 and IL-1 $\beta$ concentrations did not differ according to the diagnosis.

Table 2 shows the correlation analysis between IL-1 $\beta$ and MMP-8 levels, depending on the evaluated subgroup. As shown, there is a slight positive correlation between IL- $1 \beta$ and MMP- 8 concentrations in GCF for shallow pockets. Such a phenomenon was observed neither in healthy controls nor in deep pockets.

Table 3 shows correlations between the health index (PI - plaque index for the entire mouth) and clinical indicators of the state of periodontal tissues (BI - percentage bleeding index for the entire oral cavity, PD - maximum depth of the periodontal pocket and \% PD > $6 \mathrm{~mm}-$ percentage of pockets deeper than $6 \mathrm{~mm}$ ). No correlation was observed between the examined clinical indicators and MMP-8 and IL-1 $\beta$ concentrations in GCF.

\section{Discussion}

The non-specific component of the inflammatory response is believed to be the major factor influencing periodontal tissue destruction. Infiltration of macrophages and

Table 1. Analysis of the differences in concentrations of MMP-8 and IL-1 $\beta$ in GCF shallow (PD = 4-5 mm) and deep $(\mathrm{PD} \geq 6 \mathrm{~mm})$ pockets depending on diagnosis. $\mathrm{AP}$ - aggressive periodontitis, $\mathrm{CP}$ - chronic periodontitis

\begin{tabular}{|c|c|c|c|c|c|c|c|}
\hline & Pockets & Diagnosis & $n$ & Mean & SD & Median & $p$-value (M-W test) \\
\hline \multirow[t]{4}{*}{ MMP-8 } & \multirow{2}{*}{ Shallow } & $\mathrm{AP}$ & 16 & 35.8 & 39.3 & 21.7 & 0.130 \\
\hline & & $\mathrm{CP}$ & 33 & 49.4 & 42.0 & 41.0 & \\
\hline & \multirow{2}{*}{ Deep } & AP & 16 & 62.6 & 52.6 & 62.8 & 0.088 \\
\hline & & $\mathrm{CP}$ & 33 & 38.5 & 27.3 & 30.1 & \\
\hline \multirow[t]{4}{*}{ IL-1 $\beta$} & \multirow{2}{*}{ Shallow } & $\mathrm{AP}$ & 16 & 79.6 & 56.0 & 60.8 & 0.522 \\
\hline & & $\mathrm{CP}$ & 33 & 99.4 & 82.1 & 71.9 & \\
\hline & \multirow{2}{*}{ Deep } & $\mathrm{AP}$ & 16 & 60.8 & 35.7 & 57.9 & 0.798 \\
\hline & & $\mathrm{CP}$ & 33 & 65.8 & 44.4 & 53.4 & \\
\hline
\end{tabular}


Table 2. Correlation analysis for concentrations of IL-1 and MMP-8 in periodontitis patients and healthy controls

\begin{tabular}{lccc}
\hline Variable 1 & Variable 2 & $\begin{array}{c}\text { Pearson } \\
\text { correlation }\end{array}$ & $\boldsymbol{p}$ value \\
\hline IL-1 $\beta$ healthy & MMP-8 healthy & 0.178 & 0.509 \\
\hline IL-1 $\beta$ shallow & MMP-8 shallow & 0.309 & 0.031 \\
\hline IL-1 $\beta$ deep & MMP-8 deep & 0.167 & 0.252 \\
\hline
\end{tabular}

neutrophils to the locus of infection should result in increased concentration of the proinflammatory mediators. One can expect that inflammatory exudate, such as the GCF in the course of periodontitis, will demonstrate an elevated level of IL-1 $\beta$ and MMP-8, being the manifestation of increased activity of immunocompetent cells. Increased concentration of both measured inflammatory mediators has been reported in numerous studies [10-22]. The fact of increased concentration of both IL- $1 \beta$ and MMP- 8 in diseased persons vs healthy individuals seems undisputable. The phenomenon of similar MMP-8 concentration in shallow and deep pockets is less common.

It is even harder to explain a significantly lower concentration of IL-1 in deep than in shallow pockets, as one might expect the opposite association. Numerous reports indicate a coincidence between the pocket depth and the IL- $1 \beta$ concentration. Some of those papers mention in general the association between IL-1 $\beta$ level and progression of periodontal inflammation. Govindarajan and coworkers [12] examined 40 individuals divided into equal groups of patients suffering from chronic periodontitis and healthy controls. No correlation was found between IL- $1 \beta$ concentration and pocket depth $(p=0.316)$. Cytokine level in GCF of CP patients correlated only with two unique parameters describing the area of epithelial and inflamed tissue - PESA and PISA, respectively [12]. Lomba et al. stated that in deep pockets the level of IL- $1 \beta$ was significantly higher than in shallow ones (the included table showed exactly the opposite, but direct contact with the authors revealed that issue to result from an oversight in the table headings) [13]. Baser et al. in their publication also reported higher levels of IL-1 $\beta$ in GCF from deep pockets. Moreover, they also observed a correlation between the pocket depth and the GCF IL-1 $\beta$ level [14]. Shimada et al. observed a similar association. A higher level of IL-1 $\beta$ was observed in the GCF from diseased sites than from healthy ones. IL-1 $\beta$ level was also higher in the sites that bled on probing [15]. Summarizing the quoted manuscripts and comparing them to our own observations, we can attribute the phenomenon of lower concentration of IL-1 $\beta$ in deep pockets than in shallow pockets only to the specific (not intended, however) composition of the study group.

Similar levels of MMP-8 in fluid collected from shallow and deep pockets and higher IL- $1 \beta$ concentration in deep pockets could also be explained by measurement
Table 3. Analysis of correlations between GCF MMP-8 and IL-1 $\beta$ concentrations and clinical parameters in shallow $(\mathrm{PD}=4-5 \mathrm{~mm})$ and deep pockets $(\mathrm{PD} \geq 6 \mathrm{~mm})$. $\mathrm{PI}$ - plaque index, $\mathrm{BI}$ - bleeding index, $\mathrm{PD}_{\text {max }}$ - maximum pocket depth, $\%$ PD $>6 \mathrm{~mm}$ - percentage of pockets deeper than $6 \mathrm{~mm}$

\begin{tabular}{lcccc}
\hline & $\begin{array}{c}\text { MMP-8 } \\
\text { shallow } \\
\text { pocket }\end{array}$ & $\begin{array}{c}\text { MMP-8 } \\
\text { deep } \\
\text { pocket }\end{array}$ & $\begin{array}{c}\text { IL-1 } \beta \\
\text { shallow } \\
\text { pocket }\end{array}$ & $\begin{array}{c}\text { IL-1 } \beta \\
\text { deep } \\
\text { pocket }\end{array}$ \\
\hline $\mathrm{PI}$ & 0.43 & 0.779 & 0.791 & 0.961 \\
\hline $\mathrm{BI}$ & 0.15 & 0.731 & 0.668 & 0.603 \\
\hline $\mathrm{PD}_{\max }$ & 0.59 & 0.182 & 0.848 & 0.219 \\
\hline$\% \mathrm{PD}>6$ & 0.8 & 0.086 & 0.678 & 0.776 \\
\hline
\end{tabular}

error caused by insufficient purification of the Periotron device jaws at the next measurement. Each time, the first measurement was performed in a deep pocket and then in a shallow one. If the Periotron jaws were stained with fluid remaining from the previous measurement, it could distort the measurement of fluid from the shallow pocket. Therefore it must be assumed that fully reliable measurements are those carried out in deep pockets.

Due to the relatively high standard deviation, it is likely that in a larger study population such a phenomenon would not occur. Further examination is required to explain this. It is necessary to perform thorough cleansing of the Periotron jaws between measurements on the same patient, and to carry out measurements of shallow pockets first.

A lack of correlation between clinical indicators calculated for the entire oral cavity of the patient and MMP-8 and IL- $1 \beta$ concentrations in the pocket may indicate that the levels of the mediators depend on local inflammation. High levels of inflammatory mediators, MMP-8 and IL-1 $\beta$, were found in bleeding pockets (inflammation) in patients with periodontitis, compared to shallow non-bleeding pockets in healthy controls. Even in patients with low BI for the whole oral cavity, levels of inflammatory mediators in a single pocket can be high in response to bacteria present in the pocket. Some of these bacteria (e.g. the orange complex) may be present in increased amounts in patients with periodontitis in pockets both of a moderate depth (PD 4-5 $\mathrm{mm}$ ) and in the deep pockets $\geq 6 \mathrm{~mm}$. This in turn may lead to the development of an inflammatory reaction in the area surrounding both shallow and deep pockets.

It should also be noted that in the light of the results of the study, MMP- 8 and IL- $1 \beta$ concentrations in gingival crevicular fluid do not seem to have quite as much diagnostic significance as it was initially assumed. Assessment of inflammatory mediators' levels in saliva, which contains fluid transferred from all periodontal pockets of the patient, may be an easier method as the material is more easily available. 


\section{Conclusions}

MMP-8 and IL-1 $\beta$ concentrations in gingival crevicular fluid may indicate the activity of periodontal disease and are increased in patients with periodontitis compared to healthy individuals.

Elevated levels of MMP- 8 and IL- $1 \beta$ do not differ depending on the clinical diagnosis - aggressive or chronic periodontitis. Therefore it seems that these mediators cannot be used in diagnostic tests for differentiating these two disease entities.

This study was funded by Scientific Grant no. NN 403 582938 "The role of selected inflammatory mediators in the mechanism of formation of periodontal diseases".

The authors declare no conflict of interest.

\section{References}

1. Page RC (1991): The role of inflammatory mediators in the pathogenesis of periodontal disease. J Periodontal Res 26 (3 Pt 2): 230-242.

2. Epelman S, Lavine KJ, Randolph GJ (2014): Origin and functions of tissue macrophages. Immunity 41: 21-35.

3. Wiktor-Jedrzejczak W, Bartocci A, Ferrante Jr AW, et al. (1990): Total absence of colony-stimulating factor 1 in the macrophage-deficient osteopetrotic (op/op) mouse. Proc Natl Acad Sci U S A 87: 4828-4832.

4. Yao Z, Xing L, Qin C, et al. (2008): Osteoclast precursor interaction with bone matrix induces osteoclast formation directly by an interleukin-1-mediated autocrine mechanism. J Biol Chem 283: 9917-9924.

5. Kumar S, Millis AJ, Baglioni C (1992): Expression of interleukin 1-inducible genes and production of interleukin 1 by aging human fibroblasts. Proc Natl Acad Sci U S A 89: 4683-4687.

6. Ruscitti P, Cipriani P, Carubbi F, et al. (2015): The role of IL-1 $\beta$ in the bone loss during rheumatic diseases. Mediators Inflamm 2015: 782382.

7. Lehrer RI, Ganz T, Selsted ME, et al. (1988): Neutrophils and host defense. Ann Intern Med 109: 127-142.

8. Fujita T, Shiba H, Kurihara H (2012): Irsogladine maleate regulates barrier function and neutrophil accumulation in the gingival epithelium. J Oral Biosc 54: 79-82.

9. Armitage GC (1999): Development of a classification system for periodontal diseases and conditions. Ann Periodontol 4: $1-6$.

10. Ishihara Y, Nishihara T, Kuroyanagi T, et al. (1997): Gingival crevicular interleukin-1 and interleukin-1 receptor antagonist levels in periodontally healthy and diseased sites. J Periodontal Res 32: 524-529.

11. Engebretson SP, Grbic JT, Singer R, Lamster IB (2002): GCF IL-1beta profiles in periodontal disease. J Clin Periodontol 29: 48-53.

12. Govindarajan K, Muthukumar S, Rangarao S (2015): Relationship between interleukin $1 \alpha$ levels in the gingival crevicular fluid in health and in inflammatory periodontal disease and periodontal inflamed surface area: A correlative study. J Indian Soc Periodontol 19: 618-623.
13. Lomba KS, Beiler TF, Sete MR, et al. (2015): Use of minimally invasive gingival biopsies in the study of inflammatory mediators expression and their correlation with gingival fluid in patients with chronic periodontitis. Indian J Dent Res 26: 126-130.

14. Baser U, Oztekin G, Ademoglu E, et al. (2014): Is the severity of periodontitis related to gingival crevicular fluid and serum high-sensitivity C-reactive protein concentrations? Clin Lab 60: 1653-1658.

15. Shimada Y, Tabeta K, Sugita N, Yoshie H (2013): Profiling biomarkers in gingival crevicular fluid using multiplex bead immunoassay. Arch Oral Biol 58: 724-730.

16. Becerik S, Ozturk VO, Atmaca H, et al. (2012): Gingival crevicular fluid and plasma acute-phase cytokine levels in different periodontal diseases. J Periodontol 83: 1304-1313.

17. Baeza M, Garrido M, Hernández-Ríos P, et al. (2016): Diagnostic accuracy for apical and chronic periodontitis biomarkers in gingival crevicular fluid: an exploratory study. J Clin Periodontol 43: 34-45.

18. Kinney JS, Morelli T, Oh M, et al. (2014): Crevicular fluid biomarkers and periodontal disease progression. J Clin Periodontol 41: 113-120.

19. Chen HY, Cox SW, Eley BM, et al. (2000): Matrix metalloproteinase- 8 levels and elastase activities in gingival crevicular fluid from chronic adult periodontitis patients. J Clin Periodontol 27: 366-369.

20. Akbari G, Prabhuji ML, Karthikeyan BV, et al. (2015): Analysis of matrix metalloproteinase- 8 levels in gingival crevicular fluid and whole mouth fluid among smokers and nonsmokers using enzyme-linked immune-sorbent assay and a novel chair-side test. J Indian Soc Periodontol 19: 525-530.

21. Leppilahti JM, Sorsa T, Kallio MA, et al. (2015): The utility of gingival crevicular fluid matrix metalloproteinase- 8 response patterns in prediction of site-level clinical treatment outcome. J Periodontol 86: 777-787.

22. Victor DJ, Subramanian S, Gnana PP, Kolagani SP (2014): Assessment of matrix metalloproteinases -8 and -9 in gingival crevicular fluid of smokers and non-smokers with chronic periodontitis using ELISA. J Int Oral Health 6: 67-71. 